\title{
Relativas livres: uma proposta para o português ${ }^{1}$
}

\author{
Free relatives: an approach to portuguese
}

\section{Paulo Medeiros Júnior \\ UnB}

\begin{abstract}
The purpose of this paper is to evaluate the matter of the syntactic constructions known as free relatives and to demonstrate that the derivation of this kind of sentence holds a complex operation of functional head incorporation involving the $\mathrm{C}^{0}$ from the relative clause and the $\mathrm{D}^{0}$ selected by the matrix verb. We assume that the relative $\mathrm{CP}$ carries a relativization feature [Rel], which requires a direct relation between $\mathrm{C}$ and $\mathrm{D}$, and also postulate that this syntactical fusion is reflected in the morphological form of the wh-word in these constructions. It is also our purpose to build a structural distinction between free relatives and indirect questions in Portuguese, constructions which are commonly approximated due to an apparent similarity in structural terms.
\end{abstract}

\section{Keywords}

Free relative, Indirect question, Amalgam, Case.

\section{Resumo}

O propósito deste artigo é avaliar a questão das construções sintáticas conhecidas como relativas livres e demonstrar que a derivação desse tipo de sentença compreende uma operação de fusão de núcleos funcionais, envolvendo o $\mathrm{C}^{0}$ da relativa e o $\mathrm{D}^{0}$ selecionado pelo predicador da matriz. Entende-se que o $\mathrm{CP}$ de relativas livres seja marcado com um traço de relativização [Rel], que exige uma relação 
direta entre $\mathrm{C}$ e $\mathrm{D}$, e que a fusão sintática da qual se fala aqui tem um reflexo na forma morfológica da palavra- $Q u$ que compõe esse tipo de sentença. Implementa-se ainda uma distinção estrutural entre relativas livres e as chamadas interrogativas indiretas em português, construções que costumam ser confundidas por uma aparente similaridade em termos estruturais.

\section{Palavras-chave}

Relativa livre, Interrogativa indireta, Amálgama, Caso. 


\section{INTRODUÇÃO}

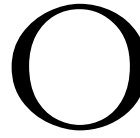

rações relativas são construções sintáticas cuja constituição apresenta uma ligação estrita entre um elemento que compõe sua estrutura e um termo na oração matriz. $O$ processo de relativização se mostra intrigante, sobretudo no que concerne a questões sintáticas, semânticas e tipológicas - questões que têm conduzido a muitos estudos sobre o tema.

Este artigo procede à análise de construções conhecidas como relativas livres (doravante RLs). Relativas livres são orações relativas que não localizam um antecedente (ou termo relativizado) expresso no contexto sintático relevante. Os dados em (1), a seguir, trazem relativas livres entre colchetes:

$$
\text { a. João convidou (para a festa) [quem você mencionou]. }
$$

b. [Quem lê Guimarães Rosa] é meu amigo.

Entende-se, de início, que relativas livres podem ser substituídas ou parafraseadas por orações relativas com antecedente, considerando-se que há uma espécie de correspondência entre essas estruturas (cf. OITICICA, 1947; ALMEIDA, 1961; BECHARA, 1994). Desse modo, uma sentença como a que se mostra em (1a), poderia ser parafraseada como em (2):

(2) João convidou (para a festa) as pessoas que você mencionou.

Entretanto, um olhar atencioso sobre a construção em (2) revela que a paráfrase elaborada para substituir a RL na posição encaixada pode não se aplicar ao conteúdo semântico da oração subordinada em (1a). O termo quem na RL pode estar sendo usado na designação de um só indivíduo no universo do discurso, dentro do conjunto daqueles que você mencionou, como se pode perceber em (3):

(3) João convidou (para a festa) aquele que você mencionou. 
Desse modo, tem-se uma questão intrigante que envolve RLs. Por se tratar de estruturas sintáticas altamente complexas (cf. DUARTE e BRITO, 2003), a literatura gerativa tem se multiplicado em torno da análise de construções dessa natureza. $\mathrm{O}$ fenômeno tem sido analisado em geral a partir de duas hipóteses de trabalho seminais, que nortearam por muito tempo a avaliação desse tipo de fenômeno sintático. São elas, a Hipótese de Base (Head hypothesis), elaborada por Bresnan e Grimshaw (1978) à qual também recorre Larson (1987) e a Hipótese do Comp (Comp hypothesis), proposta por Gross e Riemsdijk (1981), aceita por Hirshbühler e Rivero (1983) e Grosu (1996) e retomada em Riemsdijk (2000).

A Hipótese de Base propõe uma estrutura para RLs em que a palavra$Q u$ que introduz essas estruturas as encabeça, sendo gerada na base, como antecedente da sentença, algo como o que se mostra no diagrama em (4):

(4)

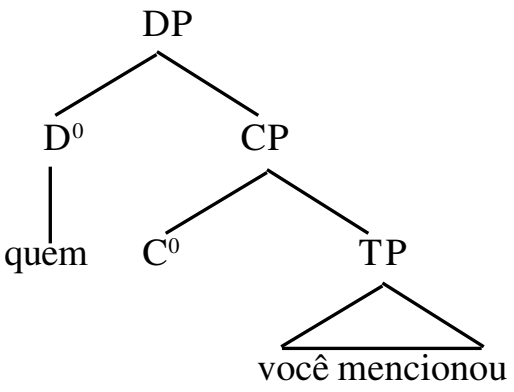

Pela Hipótese do Comp, entendeu-se que o Comp de RLs é acessível para operações que visem satisfazer exigências do predicador da matriz, e que, portanto, o sintagma- $Q u$ que se encontra nessa posição pode ser alcançado por esse predicador. O diagrama em (5) constitui a estrutura de RLs segundo essa abordagem:

(5)

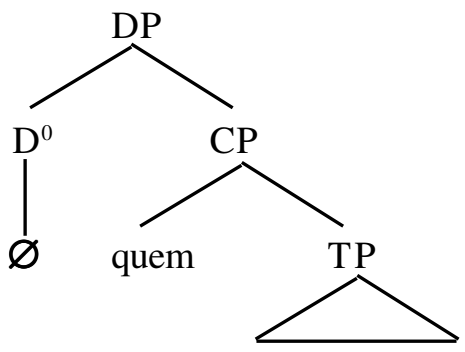

você mencionou 
Estudos mais recentes tendem a analisar RLs como DPs (cf. CAPONIGRO, 2001, 2002 e 2003; CITKO, 2004; MEDEIROS JÚNIOR, 2005b), com base na hipótese de Kayne (1994) para relativas com antecedente. A idéia de Kayne é a de que RLs são CPs que complementam um D e resultam de um processo complexo de derivação, segundo o qual o termo relativizado é extraído do interior da sentença relativa por meio de movimento.

A hipótese de trabalho deste artigo é a de que RLs sejam DPs - nos moldes do que propõem Caponigro e Citko - com uma estrutura cuja derivação envolve uma operação sintática complexa de fusão / incorporação dos núcleos funcionais $\mathrm{C}$ e $\mathrm{D}$, que se reflete na forma morfológica da palavra$Q u$ nessas estruturas. Entende-se, e tentar-se-á demonstrar, que a formação desse núcleo complexo permite explicar vários aspectos que caracterizam RLs em português. Adota-se como referencial teórico a versão da teoria gerativa conhecida como Programa Minimalista, implementada em Chomsky (1995) e desenvolvida em trabalhos subseqüentes.

\section{QUAL O PROBLEMA COM RELATIVAS LIVRES?}

O fato de serem iniciadas por uma palavra- $Q u$ costuma fazer com que RLs sejam freqüentemente confundidas com outras estruturas sintáticas que a elas se assemelham, as chamadas interrogativas indiretas (doravante PIs ${ }^{2}$ ), que aprecem destacadas nos dados em (6)

(6) a. Maria perguntou [quem João indicou para o cargo].

b. João quer saber [o que Maria comprou].

Buscando diferenciar uma construção de outra, muitos estudos chegaram a propor uma distinção por meio das propriedades selecionais do verbo da oração matriz (cf. RIEMSDIJK, 2000), o que - por algum tempo - pareceu ser a melhor solução para a questão.

Entretanto, essa idéia não se mantém em face da apreciação de sentenças como as que se colocam em (7) - com o verbo saber - em que as tais propriedades selecionais do predicador não parecem estar muito claras:

(7) a. Maria sabe [quem pegou o dinheiro na gaveta].

b. Maria sabe [se o João chega amanhã]. 
Não parece óbvio que o verbo saber selecione uma pergunta em (7a), a julgar pelo fato de que, no mesmo contexto sintático, podem surgir declarativas como em (8), ou um nominal comum - complemento - como em (9):

(8) Maria sabe [que o João é boa pessoa].

(9) Maria sabe [o caminho para a Universidade].

Não se discute o fato de que o verbo saber possa efetivamente selecionar uma pergunta - como o que se mostra em (7b). A questão que se põe é que esse verbo em especial parece se mostrar ambíguo quanto às suas propriedades selecionais (se comparados os dados em $7 \mathrm{~b}$ e 8 ), para que se possa proceder a uma imediata categorização da sentença entre colchetes em (7a) como sendo uma interrogativa indireta. Alvarenga (1981) refere-se a sentenças como a que aparece entre colchetes em (7b) como interrogativas encobertas, por entender que essas estruturas não são exatamente idênticas a outras interrogativas encaixadas típicas (como o que se tem em Ana perguntou quem fez isso), o que se deve em especial ao verbo da matriz que as seleciona; nesse caso específico, o verbo saber.

Trata-se, deste modo, de uma dificuldade para RLs a questão da diferenciação entre essas construções e as PIs.

O problema parece ser, portanto, o de determinar qual a estrutura de RLs. Considerando que tanto RLs quanto PIs são iniciadas por um sintagma$Q u$ e supondo uma derivação com movimento- $Q u$ para ambas as sentenças, não seria improvável imaginar uma analogia estrutural entre os dois tipos de construção.

\section{RELATIVAS LIVRES COMO DPS COMPLEXOS}

\subsection{Por que não a visão antiga?}

Tradicionalmente, entende-se que a derivação de uma RL, como a que aparece no dado em (1a), acontece como mostra o diagrama em (10): 


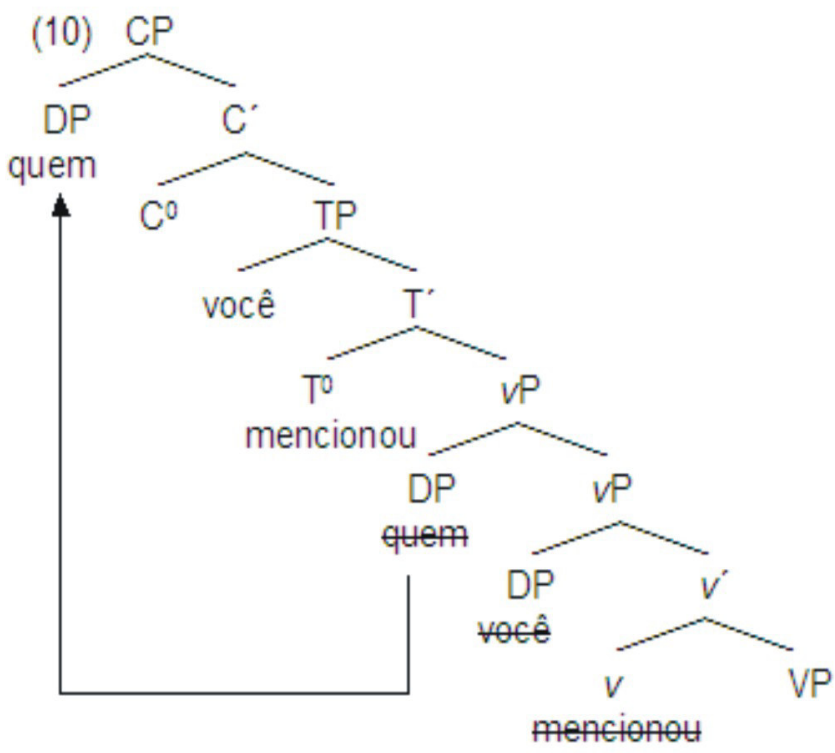

É consenso na teoria que a derivação de interrogativas - indiretas ou não envolve o deslocamento do termo- $Q u$ para a periferia da sentença por questões discursivas relacionadas à força ilocucionária (cf. MIOTO, 1994; RIZZI, 1995; BIANCHI, 1999, entre outros).

Uma idéia da derivação de RLs como a que se constrói em (10) prevê que na derivação dessas estruturas sintáticas, assim como em PIs, ocorre o deslocamento do termo ou sintagma- $Q u$ para a posição de especificador do $\mathrm{CP}$, o que conduz a uma interpretação estrutural de RLs e PIs como construções estruturalmente análogas (ROORYCK, 1994).

Caponigro (2002) propõe que RLs sejam DPs com um D silencioso complementado por um CP. Segundo essa proposta, palavras- $Q u$ em RLs encontram-se no especificador do DP, por uma necessidade de licenciar o D, que está encoberto, o que só pode acontecer em uma configuração de concordância; nesse caso, a relação Spec-head. Caponigro segue a idéia formulada em Koopman (2000), a qual propõe que as línguas não permitem que projeções sejam encabeçadas por núcleos ou Specs encobertos. Assim, para Caponigro, RLs apresentam a seguinte estrutura: 


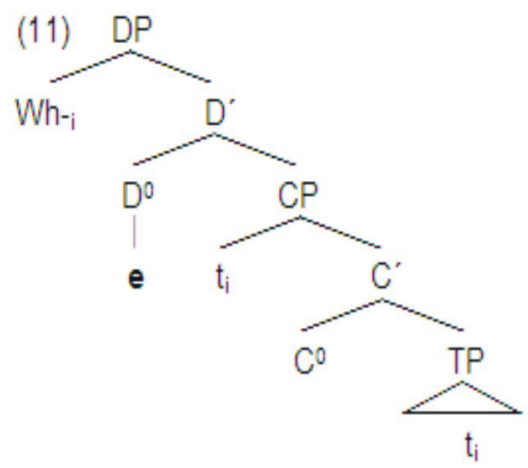

O autor entende que RLs e PIs se assemelham inicialmente, mas se opõe a hipóteses que proponham que RLs sejam CPs comuns. Uma diferença crucial entre esses dois tipos de estrutura está relacionada ao fato de que RLs nunca permitem extração, enquanto, em PIs, esse procedimento é autorizado. Os dados apresentados pelo autor para dar suporte a essa visão vêm do italiano.

(12) Extração em italiano

a. *Queste sono lê ragazze ${ }_{\mathrm{i}}$ che odio $\left[_{\mathbf{R L}} \text { chi ha invitato ragazze }\right]_{\mathrm{i}}$. Estas são as garotas que (eu) odeio quem convidou.

b. Queste sono lê ragazze ${ }_{i}$ che so $\left[_{\mathbf{P I}} \text { chi ha invitato ragazze }{ }_{\mathrm{i}}\right]_{\text {. }}$ Estas são as garotas que (eu) sei quem convidou.

\subsection{A natureza do termo-Qu em RLs}

Algumas análises do fenômeno das RLs apontam (com base nos dados do português) a ocorrência de um tipo de amálgama morfológico envolvendo palavras-Qu em RLs (cf. ROCHA, 1990; MÓIA, 1996), que seria responsável pela forma final de termos-Qu nessas estruturas. A idéia é que palavras-Qu em RLs representam a fusão morfológica entre o termo relativizado na matriz e o morfema relativizador (pronome relativo) na oração subordinada.

Segundo o que propõe Rocha (1990), em orações relativas livres, o pronome relativo é alçado de onde é gerado, pousa na posição de complemento do núcleo D e se amalgama com ele, dando origem ao sintagma-Qu final como o que se mostra em 
(João convidou [aquele + que] $\rightarrow$ quem você mencionou น

Móia (1996) propõe que palavras-Qu em RLs resultam de um amálgama morfofonológico entre o antecedente e o morfema relativizador, que integra a oração relativa, e que a forma morfológica da palavra- $Q u$ em RLs é definida por algum tipo de operação em Forma Fonológica.

No presente artigo, pretende-se formular - com base numa interpretação de relativas livres como DPs - a noção de que a forma de termos-Qu em RLs resulta de uma operação em sintaxe de incorporação dos núcleos funcionais, fato que, segundo essa visão, pode explicar uma série de peculiaridades envolvendo relativas livres e o comportamento dos sintagmas-Qu nessas estruturas.

O fato intrigante envolvendo RLs é que, tanto a posição do nominal que poderia servir de antecedente para a relativa, quanto a posição do núcleo $\left(\mathrm{C}^{0}\right)$ mostram-se absolutamente bloqueadas para a inserção de qualquer matriz fonológica, como se pode ver em:

[A Maria mencionou $\left[_{\mathbf{R L}} \varnothing\left[_{\mathbf{C P}}\right.\right.$ quem $\varnothing\left[_{\mathbf{T P}}\right.$ você viu] $\left.\left.]\right]\right]$.

Conforme o que se verá a seguir, o fato de não se poder lexicalizar o núcleo C em RLs tem uma relação direta com o que de fato parece estar acontecendo na derivação dessas estruturas e que é o cerne da proposta deste estudo.

\subsection{Uma nova abordagem: relativas livres como DPs complexos}

A proposta que se tenta defender no presente artigo está baseada na abordagem do fenômeno feita por Caponigro (2002). Passa-se a assumir que a estrutura de DP seja a mais adequada para explicar a constituição de RLs em português.

Conforme se mencionou na seção anterior, a idéia da fusão morfológica envolvendo elementos-Qu em RLs (tratada nos estudos de Móia e Rocha) é avaliada em termos da ocorrência de uma operação de amálgama sintático dos núcleos funcionais $\mathrm{C}$ e $\mathrm{D}$, que estão assumidamente relacionados de forma direta no processo de relativização (cf. VERGNAUD, 1974; KAYNE, 1994).

Para a implementação dessa visão, parte-se da proposta de Radford (2004), segundo a qual palavras- $Q u$ contêm um traço de operador, que é 
responsável por determinar a natureza dessa palavra como um operador interrogativo, relativo ou exclamativo. Propõe-se, então, que a palavra- $Q u$ em relativas contém um traço interpretável de operador relativo. Considerando-se uma versão do critério-Wh, formulado em Rizzi (1991), segundo o qual um operador semântico desse tipo precisa estar numa relação Spec-head com um núcleo portador dos mesmos traços, pode-se chegar à seguinte generalização descritiva para RLs:

(13) O núcleo $\mathrm{C}^{0}$ de relativas livres porta um traço de operador [Rel]. ${ }^{3}$

Considerando-se que a numeração de uma sentença como $O$ João mencionou quem você conhece seja a seguinte: $\mathrm{N}=\{\mathrm{o}$, João, quem, você, mencionou, conhece, $\left.\mathrm{D}_{3}, \mathrm{C}_{2}, \mathrm{~T}_{2}, v_{2}\right\}$, a derivação da RL é se constrói da maneira que se demonstra: começa-se pela subnumeração correspondente à fase $v \mathrm{P}, \mathrm{N}^{\prime}=\left\{\right.$ quem, você,conhece, $\left.\mathrm{v}_{2}\right\}$. A operação de Merge concatena o verbo conhecer e a palavra quem, formando o VP. Concatena-se em seguida $v$ com VP e tem-se a projeção de $v^{\prime}$. Nesse ponto, o verbo lexical se move para $v^{\prime} . \mathrm{O} v$ é concatenado com o constituinte você e ocorre a projeção do $v$ P. Nessa configuração, o núcleo $v$, que porta traços $p h i$ não-interpretáveis, identifica ou sonda o DP quem, com traços phi disponíveis para checagem, estabelecendo-se a operação agree entre $v$ e o DP. Como resultado da operação agree nesse domínio sintático, o DP quem tem seu traço de Caso valorado como acusativo. A estrutura até esse ponto da derivação é a que se vê em (14):

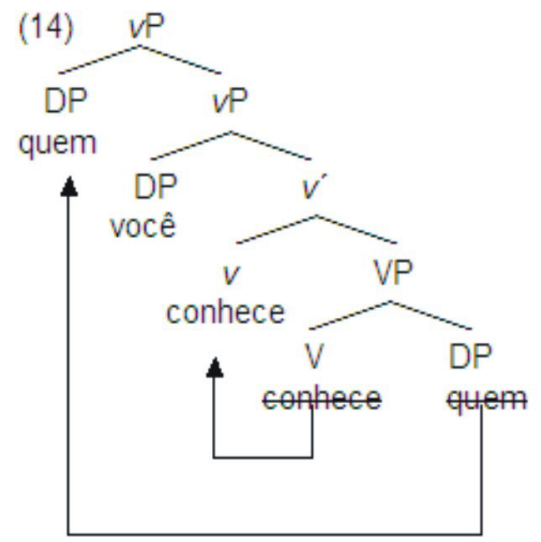


Em seguida, é selecionada a subnumeração correspondente à fase $\mathrm{CP}$, que é $\mathrm{N}^{\prime \prime}=\left\{\mathrm{C}_{1}, \mathrm{~T}_{1}, v \mathrm{P}\right\}$. Concatena-se o núcleo $\mathrm{T}^{0} \operatorname{com} v \mathrm{P}$ e o verbo sobe para $\mathrm{T}$. $\mathrm{T}^{0}$ é marcado com traços- $\varphi$ não interpretáveis e um traço EPP $;^{4}$ passa, portanto, a agir como sonda, que sai à procura de um elemento capaz de checar esses traços. O DP você está disponível, possui traços- $\varphi$ compatíveis e um traço de Caso que não foi checado. Ocorre agree e os traços relevantes de $\mathrm{T}^{0}$ são valorados, bem como o traço de Caso de você. Um traço EPP nesse núcleo funcional força o alçamento de você para a posição de especificador do $\mathrm{T}^{0}$, projetando o TP; por ser T a categoria com a qual o DP você estabelece agree, esse DP recebe Caso nominativo.

Nesse ponto, o núcleo $\mathrm{C}^{0}$ é concatenado a TP. Conforme mencionado, o núcleo $\mathrm{C}^{0}$ entra na derivação portando um traço [Rel], além do traço EPP. $\mathrm{O}$ traço [Rel] em $\mathrm{C}^{0}$ requer uma palavra- $Q u$ com o traço de operador correspondente; a sonda localiza quem na derivação que é compatível em termos de traços; o traço EPP em $\mathrm{C}^{0}$ exige que quem seja concatenado em Spec-CP; esse procedimento se dá por merge interno. ${ }^{5}$ Projeta-se então o CP. A estrutura relevante para esse estágio da derivação é a seguinte:

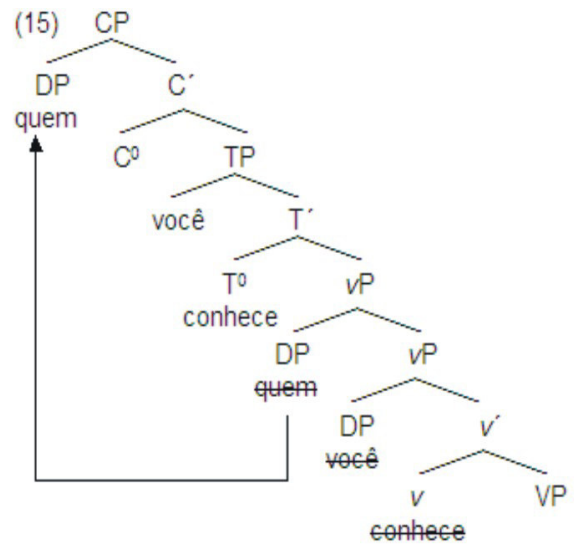

Está formado o $\mathrm{CP}$, que na fase seguinte será concatenado como complemento do núcleo funcional $\mathrm{D}^{0}$, constituindo-se assim a estrutura relativa (livre).

A subnumeração referente à próxima fase $v \mathrm{P}$ é a seguinte:

$\mathrm{N}^{\prime \prime \prime}=\left\{\right.$ mencionou, $v_{2}, \mathrm{o}$, João, $\left.\mathrm{D}\right\}$. 
Partindo do pressuposto de que o núcleo $\mathrm{C}^{0}$ é marcado com o traço de operador relativo [Rel], supõe-se que esse traço requer concatenação com um núcleo $\mathrm{D}^{0}$. A essa exigência acrescenta-se a hipótese formulada em Caponigro (2001), segundo a qual núcleos funcionais sem realização fonológica precisam estar numa relação Spec-head com elementos realizados e entendese que, por essa razão, a palavra-Qu precisa ser alçada a Spec-DP (a partir de Spec-CP), para licenciar o núcleo D vazio nessa configuração.

$\mathrm{O}$ fato de existir na derivação um item lexical - quem - que satisfaz às propriedades de dois núcleos funcionais distintos $\left(\mathrm{C}^{0} \mathrm{e} \mathrm{D}^{0}\right)$, associado à impossibilidade de lexicalização do $\mathrm{C}^{0} \mathrm{em}$ RLs ou da posição do nominal na matriz que as subordina (como se demonstrou no final da seção 3.2) serve como evidência para a postulação de que a forma morfológica desse item reflete uma operação de incorporação dos núcleos funcionais C e D (nos termos do que assevera Baker, 1988). Como propõe Baker (p.428), os princípios da morfologia não se constituem numa subparte de qualquer nível da gramática como o Léxico ou a Forma Fonológica; antes, constituem componente semi-independente da gramática, que, como tal, exigem representações em qualquer um ou em todos os níveis de descrição lingüística. Assim, a estrutura de RLs segundo essa proposta é seguinte: ${ }^{6}$

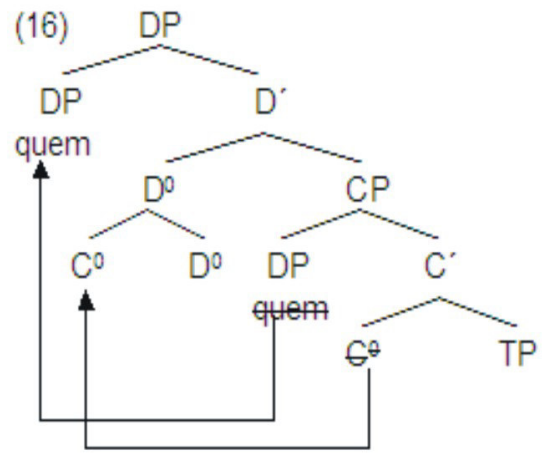

Com essa análise, é possível dar conta da agramaticalidade de construções como a que aparece em (17), em que se verifica a impossibilidade de se inserir antecedente nominal em RLs, bem como a agramaticalidade da construção em (18), por não se poder inserir a partícula que após o sintagma- $Q u$ : 
*O João entrevistou a moça quem cometeu o crime.

*O João entrevistou quem que cometeu o crime.

Como se pode observar, em (17), a sentença é agramatical devido à presença simultânea de $a$ moça, DP que funciona como complemento do verbo da matriz, e quem, termo- $Q$ u que compõe a oração relativa. Se se supõe que a palavra- $Q u$ subiu para $\mathrm{D}$, a ocorrência do termo a moça nesse contexto sintático passa a ser inviabilizada.

O dado em (18) é agramatical pela presença do morfema que imediatamente após o sintagma-Qu, que se supõe ter sido alçado a essa posição. Observe-se que, em interrogativas indiretas, a presença desse elemento é perfeitamente viabilizada como em $O$ Pedro perguntou [quem que procurou por ele]. Se estiver correta a suposição de que em RLs o $\mathrm{C}^{0}$ se incorporou ao D da matriz, talvez se possa explicar a impossibilidade da inserção do morfema que nessa posição pelo fato de o núcleo não se encontrar mais disponível - naquela posição - para que possa ser lexicalizado. ${ }^{7}$

Avaliando o diagrama em (16) e levando em conta a análise dos dados em (17) e (18), considera-se que a impossibilidade de inserção do morfema que e da realização do antecedente em RLs viabiliza uma hipótese de que a palavra- $Q u$ nessas construções corresponde, na verdade, a um amálgama das posições sintáticas em que ocorreriam o antecedente e o morfema relativizador. Assim, palavras- $Q u$ em RLs seriam constituídas a partir de uma operação sintática e não resultantes de uma fusão morfológica ${ }^{8}$.

Apontam-se, portanto, duas evidências para a postulação de uma operação de incorporação de núcleos na derivação de relativas livres, uma indireta e outra absolutamente perceptível nos dados:

Evidência 1 (indireta): há na derivação um só item lexical que satisfaz às propriedades de $\mathrm{C}$ e $\mathrm{D}$.

Evidência 2: as posições do nominal anterior ao sintagma-Qu e do núcleo $\mathrm{C}^{0} \mathrm{em}$ RLs encontram-se bloqueadas para a inserção de quaisquer elementos.

A compreensão do fenômeno das RLs como DPs acaba por corroborar a hipótese de Vergnaud sobre o processo de relativização, pois se entende que RLs e relativas com antecedente são estruturas paralelas, resultantes de 
processos análogos de estruturação, fato que é compatível com a compreensão dos mecanismos da gramática como resultantes de processos mentais que se aplicam dentro de certos padrões de regularidade.

Um argumento para motivar a análise de RLs como estruturas D pode ser formulado considerando-se a questão da distribuição. Sejam os dados em (19) e (20):

(19) a. João implica com as pessoas que você convida (para as festas).

b. João implica com as CV que você convida (para as festas).

c. João implica com quem você convida (para as festas).

d. * João implica com ø que você convida.

(20) a. As pessoas que disseram isso não são importantes.

b. As CV que disseram isso não são importantes.

c. Quem disse isso não é importante.

d. ø Que disse isso não é importante.

Assumindo-se a estrutura em (16), ou seja, se se interpreta a RL como um DP que envolve uma operação de incorporação dos núcleos C e D, temse que esse DP recebe Caso. Nos exemplos em (19d) e (20d), as sentenças em posição argumental são CPs comuns. ${ }^{9}$

\section{UM PROBLEMA PARA ESSA ANÁLISE}

A implementação de uma proposta com essas características traz um problema para a teoria, que é o de ter, no decurso da derivação da RL, um item lexical que recebe Caso duas vezes. Numa sentença como a que se analisou nos diagramas em (14), (15) e (16), quem, o constituinte- $Q u$ movido, já tendo seu traço de Caso checado, pousa numa posição em que pode receber Caso novamente do predicador da matriz.

(21) O João mencionou $\left[_{\mathbf{D P}}\right.$ quem ${ }_{\mathrm{i}} \mathrm{C}_{\mathbf{C P}} t_{\mathrm{i}} \mathrm{I}_{\mathbf{T P}}$ você conhece ]]]

A questão da dupla atribuição de caso à palavra- $Q u$ tem recebido algum tratamento em trabalhos como os de Vogel (2001, 2002 e 2003). ${ }^{10}$ Para esse autor, a questão da dupla atribuição de Caso ao sintagma- $Q u$ em RLs só pode ser explicada em termos de último recurso. A matriz, segundo ele, não teria 
outro DP sobre o qual descarregar seus traços de Caso, a não ser a palavra$Q u$ movida àquela posição. A derivação só pode ser salva se esse DP receber os traços de Caso que precisam ser descarregados pelo predicador da matriz, que é o que de fato ocorre.

Entretanto, para a abordagem de RLs que se constrói no presente artigo, a questão da dupla atribuição de Caso é apenas aparente. Nos termos do que se propõe, o que de fato acontece é que, se a hipótese de uma operação de fusão de núcleos funcionais estiver correta, na derivação, o sintagma ou palavra- $Q u$ satisfaz as exigências de Caso do verbo na subordinada e, após a derivação de toda a sentença relativa, tendo-se uma espécie de DP complexo, o traço de Caso do predicador mais alto pode ser descarregado no núcleo $\mathrm{D}$ do complexo [D+C]. Em (22) pode-se ver o resultado de forma simplificada:

(22)

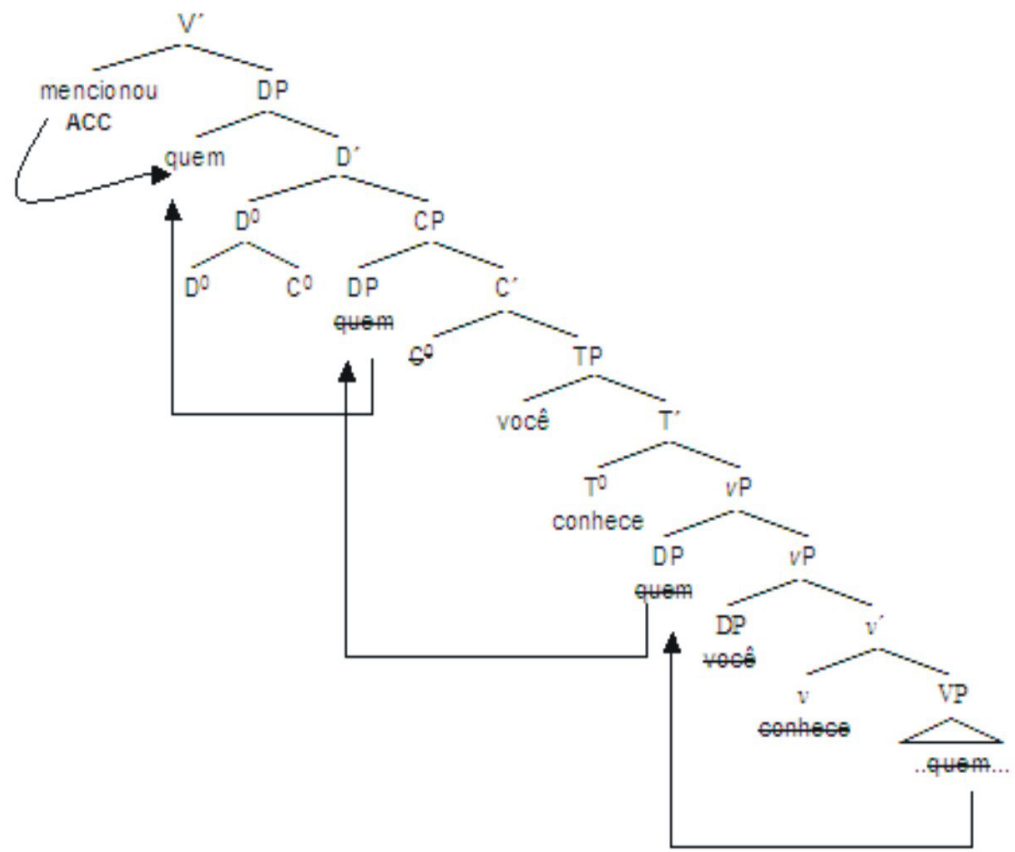

Uma outra maneira de abordar o fenômeno seria assumir com Chomsky (2005) que, na relação C-T como a que se mostra aqui, não se tem efetivamente a projeção de C, mas do próprio termo- $Q u$. Sendo que se trata de um DP, o 
que se tem é que a etiqueta da projeção vai ser DP e o resultado é a relativa livre. Pode-se então supor que, nesse ponto, a RL como um todo recebe Caso do predicador da matriz.

(23) O João mencionou [ ${ }_{\mathbf{D P}}$ quem você conhece].

\section{SOBRE INTERROGATIVAS INDIRETAS}

Ao se tratar das propriedades estruturais e semânticas de RLs, indiretamente se constrói uma separação entre esse tipo de construção sintática e as PIs.

A tradição gerativista convencionou designar o especificador do $\mathrm{CP}$ como a posição para a qual se desloca esse termo em interrogativas (cf. LASNIK; SAITO, 1992). Segundo o que se entende, C é uma categoria funcional que se projeta formando a categoria sintagmática $\mathrm{CP}$. A posição de especificador de CP não é uma posição argumental - é uma posição não$\operatorname{argumental}\left(\mathrm{A}^{\prime}\right)$ - onde pousam elementos- $Q u$ que se movem. Levando-se em conta uma análise com esse aparato teórico, a estrutura para a sentença interrogativa como a que aparece em João perguntou quem Pedro viu no parque é a seguinte:

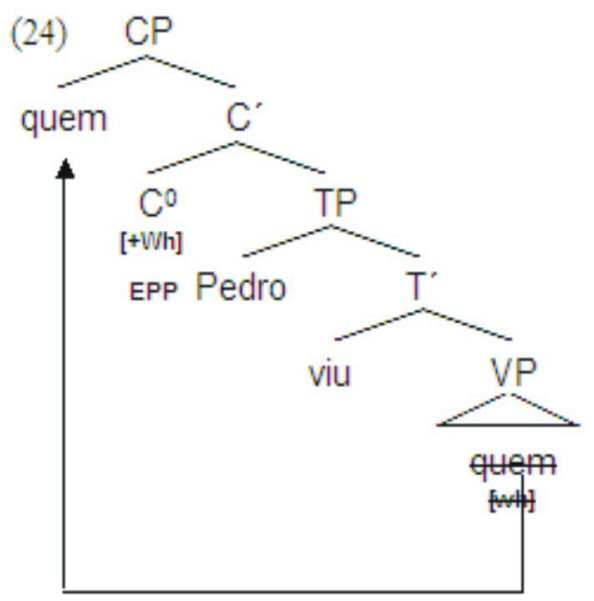

Sendo o núcleo $\mathrm{C}^{0}$ marcado com o traço [+wh], após a aplicação de agree e o apagamento dos traços relevantes, a palavra- $Q u$ se desloca para o Spec- 
CP para satisfazer EPP e a força em C tipifica essa sentença como uma interrogativa (cf. CHENG, 1991). Note-se que há uma compatibilidade entre os traços do núcleo que sonda e os do item lexical que serve de alvo.

Entende-se, seguindo Rizzi (1995), ${ }^{11}$ que em interrogativas diretas do tipo Quem João viu? a palavra-Qu esteja sendo focalizada, situação que decorre da incorporação de I em Foc, categoria funcional que se supõe estar presente em C.

As PIs, entretanto, apresentam propriedades um pouco diferentes. Segundo Rizzi, o pronome interrogativo não pode seguir o constituinte marcado com foco. ${ }^{12} \mathrm{O}$ que acontece é que o traço [+wh] é diretamente selecionado pelo verbo da matriz em estruturas desse tipo. Assim, o "pronome interrogativo" tem de estar imediatamente adjacente ao predicador da matriz. Em sentenças como as que se mostram em (25) e (26), a impossibilidade de focalização de um elemento entre o predicador da matriz e o termo interrogativo gera a agramaticalidade das estruturas:

$$
\text { *Quero saber }\left[_{\mathrm{Foco}} \mathrm{O}\right. \text { JOÃO] quem viu___. }
$$

*Ela perguntou $\left[_{\mathrm{Foco}}\right.$ A COMIDA] quem fará

Os dados conduzem à postulação de que em PB o "pronome interrogativo" em PIs precisa estar em Spec-CP, imediatamente adjacente ao verbo da matriz. Tem-se, dessa forma, que termos- $Q u$ em RLs e em PIs encontram-se em configurações distintas.

Essa diferença estrutural certamente tem ligação com o fato de que se considera ter havido em RLs um amálgama sintático entre o núcleo do DP externo ao $\mathrm{CP}$ da relativa e o núcleo $\mathrm{C}^{0}$ da relativa (conforme se argumentou anteriormente). PIs não podem conter uma operação sintática dessa natureza por razões simples: o predicador da matriz - nesses casos - não seleciona um $\mathrm{D}$ que contenha um $\mathrm{CP}$ como complemento, mas um $\mathrm{CP}$ marcado com o traço [+wh], cujo operador interrogativo precisa se encontrar em adjacência estrita ao predicador na oração estruturalmente mais alta.

De forma resumida, a diferença estrutural entre RLs e PIs pode ser vista nos diagramas em (27) e (28), logo a seguir:

João indicou (para o cargo) [quem você conhece__ ]. 
Relativa Livre

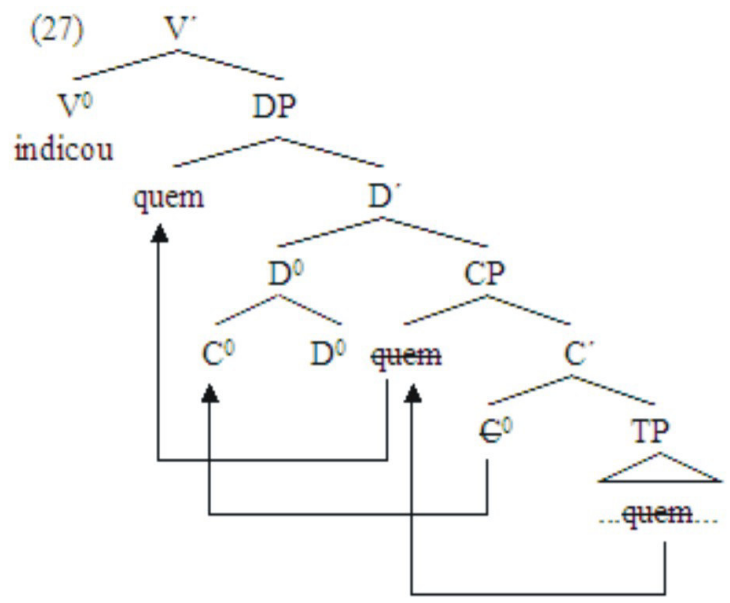

João perguntou [quem você conhece ].

Interrogativa Indireta

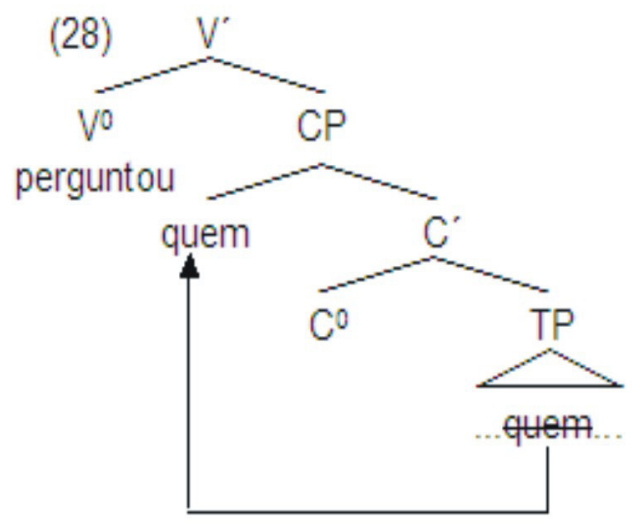

Uma evidência sintática que se pode apresentar para a distinção estrutural aqui proposta entre RLs e PIs está no fato de que PIs admitem, no decurso da derivação, o pied-piping da preposição que eventualmente integre o sintagma- $Q u$, enquanto em RLs esse procedimento é bloqueado, conforme evidenciam os dados em (29) e (30): 
(29) a. Maria perguntou [[de quem $]_{\mathrm{i}}$ você gosta $\left.t_{\mathrm{i}}\right]$.

b. Maria quer saber [[por quem $]_{\mathrm{i}}$ você se interessa $\left.t_{\mathrm{i}}\right]$.

(30) a. *João indicou (para o cargo) [[de quem $]_{i}$ você mais gosta $\left.t_{i}\right]$.

b. *João convidou (para a festa) [[por quem $]_{i}$ você se interessa $\left.t_{i}\right]$.

Essa questão está certamente relacionada ao problema do Caso discutido na seção $4 .{ }^{11}$ Em RLs, a preposição alçada com a palavra- $Q u$ intervém e o verbo da matriz não consegue descarregar seus traços de Caso. Em PIs, considerando toda a argumentação construída anteriormente sobre as interrogativas e partindo da hipótese de que não ocorre um amálgama com as características e o Status do que se apresenta em RLs, o problema do Caso não se põe.

\section{UMA QUESTÃO REMANESCENTE}

Posto dessa forma, o caso do alçamento da preposição em RLs parece não apresentar problema algum. A realidade, entretanto, demonstra que não se trata de algo tão simples. A observação dos dados em (31), (32) e (33) pode revelar um problema para a proposta que tem sido desenvolvida até esse ponto da argumentação. Sejam os dados:

(31) a. João tem $\left[\left[_{\mathrm{PP}} \text { com quem }\right]_{\mathrm{i}}\right.$ conversar $\left.t_{\mathrm{i}}\right]$.

b. Maria tem $\left[\left[_{\mathbf{P P}} \text { com quem }\right]_{\mathrm{i}}\right.$ desabafar $\left.t_{\mathrm{i}}\right]$.

(32) a.Maria não acha $\left[\left[_{\mathbf{P P}} \text { com quem }\right]_{\mathrm{i}}\right.$ desabafe $\left.t_{\mathrm{i}}\right]$.

b. João não tem $\left[\left[_{\mathbf{P P}} \text { com quem }\right]_{\mathrm{i}}\right.$ se distraia $\left.t_{\mathrm{i}}\right]$.

(33) a. João não tem $\left[\left[_{\mathbf{P P}} \text { do que }\right]_{\mathrm{i}}\right.$ possa reclamar $\left.t_{\mathrm{i}}\right]$.

b. Maria não acha $\left[\left[_{\mathbf{P P}} \text { com quem }\right]_{\mathrm{i}}\right.$ possa conversar $\left.t_{\mathrm{i}}\right]$.

Como se pode ver, com orações infinitivas como em (31), com orações que apresentem verbos no subjuntivo, como em (32), ou nas construções com auxiliares modais no subjuntivo, como em (33), o alçamento da preposição é autorizado. O que parece estar acontecendo é que orações relativas livres que possuem uma forma verbal irrealis como nos dados apresentados se comportam como interrogativas indiretas, permitindo o alçamento da preposição (cf. discussão a esse respeito em Izvorski, 1998; Grosu e Landman, 1998; Caponigro, 2003 e Medeiros Júnior, 2005b). 
Em todos os estudos que tratam da dificuldade levantada, a atitude é muito mais descritiva do que explicativa. Persiste, portanto, a questão de explicar por que o alçamento do sintagma- $Q u$ preposicionado é possível, o que implicaria dizer que RLs irrealis não manifestam nenhum tipo de efeito de combinação (especialmente no que diz respeito à questão do Caso). Essa questão permanece em aberto para investigações futuras.

\section{CONSIDERAÇÕES FINAIS}

Relativas livres são estruturas D com um D silencioso que toma um CP por complemento. A derivação de RLs envolve movimento de $\mathrm{C}$ para $\mathrm{D}$ e uma operação de fusão dos núcleos funcionais $\mathrm{C} \mathrm{e} \mathrm{D.} \mathrm{Com} \mathrm{as} \mathrm{idéias} \mathrm{desenvolvidas}$ neste trabalho, postulou-se que o CP de RLs é marcado com um traço de relativização, que se denominou [+Rel] e que a presença desse traço específico em $\mathrm{C}^{0} \mathrm{em}$ articulação com a exigência de que núcleos funcionais vazios devem ser realizados fonologicamente propicia a fusão dos núcleos funcionais. Essa operação sintática complexa tem um correlato morfológico, que é a forma que a palavra- $Q u$ assume em estruturas dessa natureza.

A análise em termos do amálgama sintático permitiu ainda dar conta da impossibilidade do pied-piping da preposição em RLs, diferentemente de PIs, que autorizam essa operação sintática.

Considerando-se que a palavra- $Q u$ se desloca para a posição de especificador do núcleo complexo [D + C], formado por fusão / incorporação sintática, entende-se que deve haver a combinação de traços formais entre esses elementos. Assim, em construções como * Maria indicou (para o cargo) de quem João gosta, a palavra- $Q u$, sendo marcada pelo traço de Caso inerente da preposição, não pode ser licenciada na posição de especificador do núcleo complexo $[\mathrm{D}+\mathrm{C}]$, em que o núcleo $\mathrm{D}^{0}$ é marcado por Caso acusativo no domínio sintático do $v$ da matriz.

Uma questão remanesce quanto ao comportamento sintático de relativas livres: o que faz certos tipos de RLs - em especial aquelas que apresentam uma forma verbal que contém um traço irrealis - autorizarem o pied-piping da preposição em detrimento das construções marcadas com verbos marcados pelo traço realis - que definitivamente não autorizam esse tipo de operação sintática? 


\section{NOTAS}

${ }^{1}$ Meus sinceros agradecimentos aos amigos pesquisadores Heloísa Salles, Jairo Nunes, Cilene Rodrigues, Carlos Mioto e Marcus Lunguinho, por seus preciosos comentários e sugestões. Um agradecimento mais do que sincero à inesquecível Lúcia Lobato, pelo auxílio com a bibliografia, suas observações sempre oportunas e por sua incansável dedicação à pesquisa. À Lúcia, muito mais do que a gratidão pelo apoio em um trabalho, mas o sincero reconhecimento de toda uma vida dedicada à pesquisa e à busca da compreensão do funcionamento da mente humana pela manifestação da linguagem.

${ }^{2} \mathrm{P}$ para pergunta e I para indireta.

${ }^{3}$ Provavelmente o núcleo $\mathrm{C}^{0}$ de orações relativas com antecedente também porta o traço formal [Rel].

${ }^{4}$ Em Chomsky (2005), apresenta-se uma visão um pouco diferente dessa. A idéia é que existe uma relação entre os núcleos $\mathrm{C}$ e $\mathrm{T}$, que é a que cria a sonda perfeita para os alvos relevantes, considerando-se que se entende que o merge interno (ou move) só pode ser forçado por um item lexical que seja núcleo de uma fase. Chomsky propõe que, na verdade, $\mathrm{C}$ contenha traços de concordância (que herda quando seleciona um T com traços- $\varphi$ ) e um traço de borda, que vai ser responsável pela projeção do especificador.

${ }^{5}$ Cf. Chomsky (2001) para uma diferenciação entre merge interno e merge externo.

${ }^{6}$ Observe-se que, com essa idéia, preserva-se a noção de que apenas o núcleo de uma fase e seu especificador estão disponíveis para operações em outra fase, tal como se encontra expresso em Chomsky (1999).

${ }^{7}$ Note-se que a discussão nesse ponto não se constitui sobre a viabilidade de lexicalização do núcleo $\mathrm{C}^{0} \mathrm{em}$ RLs, mas da realização de material fonológico naquela posição específica após a ocorrência da incorporação de C em D. A derivação de RLs com ever em inglês, por exemplo, pode servir como evidência concreta de que esse processo de incorporação pode envolver núcleos funcionais fonologicamente realizados. Observe-se que o sintagma-Qu, nesses casos, passa a apresentar uma forma morfológica que corresponde à fusão dos núcleos funcionais envolvidos no processo de incorporação. Seja o dado em

(i) Peter will congratualte [who[ever]] passes these exams. 
Aqui, conforme se argumentou, o sintagma-Qu se constitui de uma palavra wh típica unida à partícula ever. A idéia é a de que who represente a lexicalização de $\mathrm{C}^{0}$ e ever a lexicalização de $\mathrm{D}^{0}$ (Informação obtida em comunicação pessoal com Jairo Nunes). A discussão é constituída, portanto, no sentido de mostrar que sentenças como a que aparece em (18) são agramaticais porque não há mais a possibilidade de lexicalizar o núcleo $\mathrm{C}^{0}$ à parte do material fonológico de $\mathrm{D}^{0}$.

${ }^{8}$ Para uma visão da avaliação de fenômenos localizados na interface sintaxemorfologia, cf. Embic \& Noyer (2001 e 2004).

${ }^{9}$ Põe-se aqui de lado a discussão que pode decorrer da análise de estruturas completivas comuns como em $O$ Pedro disse [que a Maria virá], em que se tem um CP comum (que Maria virá) em posição argumental e, portanto, uma situação em que não se tem os traços de Caso do verbo da matriz sendo descarregados.

${ }^{10}$ Uma característica notável de relativas livres é o chamado efeito de combinação (matching effect, nos termos de Bresnan e Grimshaw 1978). Bresnan e Grimshaw (1978), Larson (1987) e Hirshbühler e Rivero (1983) tratam de um efeito de combinação categorial envolvendo RLs. Alguns trabalhos sobre o tema têm tentado discutir essa questão assegurando que RLs estão sujeitas a um certo efeito de combinação de Caso, o qual assegura que o Caso que a palavra ou sintagma- $Q u$ recebe na relativa tem de ser idêntico ao Caso que esse elemento receberá na oração matriz, sob pena de não ocorrer a convergência da derivação da sentença (cf. SAUERLAND, 1996; IZVORSKI, 1996; VOGEL, 2001, 2002 e 2003; KUBOTA, 2003; MEDEIROS JÚNIOR, 2005a; MEDEIROS JUNIOR, 2006; CITKO, 2005).

Trabalhos como o de Vogel (2003) fazem uma avaliação de línguas que exibem Caso morfológico, apontando a necessidade do Matching entre o Caso atribuído ao elemento-wh na matriz e na subordinada. Para Vogel, as línguas elegem parametricamente estratégias para adequar a estrutura quando ocorrem conflitos de caso (mismatching) envolvendo o predicador da matriz e o da sentença relativa. Algumas das estratégias que as línguas adotam para resolver os conflitos de caso seriam basicamente as seguintes: certas línguas realizam no elemento- $Q u$ o caso atribuído na matriz e deixam o da subordinada sem ser realizado - como acontece em islandês e no grego moderno; o dado em (i), do islandês, ilustra essa ocorrência (o trabalho de Citko, 2005, também faz referência a esse dado). Em línguas como o alemão, o caso da relativa precisa ser realizado e o da matriz apagado para que se resolva o conflito, como se vê em (ii). Alguns dialetos do alemão simplesmente apagam o caso da matriz; em outros, como o que se vê em (iii), ocorre uma espécie 
de hierarquia de caso segundo a seguinte ordem: Nominativo < Acusativo < Dativo, Genitivo, PP. Assim, já que o pronome da RL tem de receber o caso da subordinada em alemão, RLs não podem ocorrer, nesses dialetos específicos, se o caso atribuído na matriz for mais alto que o caso atribuído na relativa. Considerese o dado a seguir (apresentado por Vogel, op.cit., p.277) de um dialeto do alemão em que ocorre a hierarquia de caso:

a. ég hjálpa hverjum/ *hvern (sem) ég elska

'I help who-DAT/ who-ACC (that) I like'.

b ég elska *hverjum/ hvern

(sem) ég hjálpa

'I like who-DAT/ who-ACC (that) I help

(ii) a. Ich lade ein, wem ich vertraue

'I invite who-DAT I trust'.

b. *Ich vertraue, wen ich einlade

'I trust who-ACC I invite'.

(iii) a. caso na matriz $=\mathrm{ACC}-$ caso na relativa $=\mathrm{NOM}$

* Er zerstörte, wer ihm begegnete

He destroyed who-NOM him - DAT met

'He destroyed who met him'

b. caso na matriz $=\mathrm{NOM}-$ caso na relativa $=\mathrm{ACC}$

Ihm begegnete, wen er zerstören wollte

Him - DAT met who-ACC he destroy wanted

'Him met who he wanted to destroy'

Algumas línguas optariam por uma estratégia de correlativização - como se dá em coreano; o pronome da RL permanece in situ e um pronome resumptivo dentro da matriz é obrigatório:

(iv) Maria-ka nuku-eke ka-tunchi na-to ku-eke ka-n-ta

Maria-NOM who-DAT go-ever I-also he-DAT go-Pre-Dec

'To whoever Maria goes, I will go to him too'

${ }^{11}$ A análise de Rizzi (1995) se baseia em dados da língua inglesa. Medeiros Junior (2005b) demonstra que o PB tem comportamento semelhante ao do inglês nesse aspecto. Cabe ressaltar que uma análise do italiano encontrada em Bianchi (1999) demonstra que, nessa língua específica, palavras- $Q u$ em interrogativas indiretas parecem estar em Foc. 
${ }^{12} \mathrm{O}$ que se encontra em Miyagawa (2005) é um pouco diferente dessa idéia; para esse autor, o movimento- $Q u$ está relacionado ao que ele chama de parâmetro Focus-Agreement. Para Miyagawa, foco e concordância são considerados duas polaridades do mesmo parâmetro, e ambos os traços localizados em C interagem com EPP, o que resulta em variação paramétrica entre as línguas.

\section{REFERÊNCIAS}

ALMEIDA, N. M. de. Gramática Metódica da Língua Portuguesa. 13. ed. São Paulo: Saraiva, 1961.

ALVARENGA, Daniel. Sobre interrogativa indireta no português. 1981. Dissertação (Mestrado) - Universidade Federal de Minas Gerais, Belo Horizonte.

BAKER, M. Incorporation. Chicago: The University of Chicago Press, 1988.

BECHARA, E. Moderna Gramática Portuguesa. 35. ed. São Paulo: Companhia Editorial Nacional, 1994.

BIANCHI, V. Consequences of antisymmetry: headed relative clauses. Berlin: Mouton de Gruyter: 1999.

BRESNAN, J.; GRIMSHAW, J. The Syntax of Free Relatives. English Linguistic Inquiry 9, p. 331-391, 1978.

CAPONIGRO, I. On the semantics of indefinite free relatives. In: KOPEN, M. V.; SIO, J.; De VOS, M. (Eds.). Proceedings of ConSOLEX. Leiden: SOLE. p. 49- 62, 2001.

CAPONIGRO, I. Free Relatives as DPs with a Silent D and a CP Complement. In: SAMIIAN, V. (Ed.). Proceedings of the Western Conferences on Linguistics, 2000 (WECOL 2000), Fresno, California: California State University, 2002.

CAPONIGRO, I. The Semantic contributions of Wh-words and Type Shifts: Evidence from Free Relatives Crosslinguistically. Proceedings of Semantics and Linguistic Theory (SALT) XIV. Itaca, NY: CLS Publications, Cornel University, 2003.

CHOMSKY, N. The Minimalist Program. Cambridge, MA: MIT Press, 1995.

CHOMSKY, N. Derivation by Phase. MIT working papers in Linguistics 18, MIT, Cambridge, Mass, 1999. 
CHOMSKY, N. Beyond Explanatory Adequacy. MIT Occasional Papers in Linguistics 20, MIT, Cambridge, Mass, 2001.

CHOMSKY, N. On Phases, 2005. MS.

CITKO, B. On Headed, Headless and Light-headed Relatives. Natural Language and Linguistic Theory, v. 22, p. 95-126, 2004.

CITKO, B. What Don't Wh-Questions, Free Relatives, and Correlatives Have in Common? 2005. MS. Disponível em: <http://faculty.washington.edu/bcitko/ index_files/Page424.html> Acesso em: 8/7/2006.

CHENG, L. L. S. On the typology of wh-questions. Doctoral Dissertation, MIT, 1991.

DUARTE, I.; BRITO, A. M. Orações relativas e construções aparentadas. In: MATEUS, M. H. et al. Gramática da Língua Portuguesa. Lisboa: Caminho, 2003. p. 655-694.

EMBICK, D.; NOYER, R. Movement Operations after Syntax. Linguistic Inquiry 32: 4, p. 555-595, 2001.

EMBICK, D.; NOYER, R. Distributed Morphology and the Syntax/Morphology Interface. In: RAMCHAND, G.; REISS, C. (Eds.) The Oxford Handbook of Linguistic Interfaces. Oxford University Press, 2004.

GROSS, A.; RIEMSDIJK, H. V. Matching Effect in Free Relatives: A parameter of Core Grammar. In: Proceedings of Pisa Coloquium on Markedness, Annali dela Scuola Normale superiore, Pisa, 1981.

GROSU, A. 'On the Proper Analysis of "Missing P” Free Relative Constructions'. Linguistic Inquiry 27, p. 41-58, 1996.

GROSU, A.; LANDMAN, F. Strange relatives of the third kind. Natural Language Semantics, 6. p. 125-170, 1998.

HIRSHBÜHLER, P.; RIVERO, M. L. Remarks on Free Relatives and matching phenomena. Linguistic Inquiry, 14 (3), 1983.

IZVORSKI, R. Matching Effects in Free Relatives and pro-Drop. University of Pennsylvania, USA. MS, 1996.

IZVORSKI, R. Non-Indicative Wh-Complements of Possessive and Existential Predicates. In: TAMANJI, P. N.; KUSUMOTO, K. (Eds.) Proceedings of NELS 28, p. 159-173, 1998. 
KAYNE, R. The Antisymmetry of Syntax. Linguistic Inquiry Monographs, 25. Cambridge, MA: MIT Press, 1994.

KOOPMAN, H. The Spec Head Configuration. In: KOOPMAN, H. The Syntax of Specifiers and Heads: Controlled essays of Hilda J, Koopman. London-New York: Routledge, 2000.

KUBOTA, Y. Yet another HSPG - Analysis for Free Relative Clauses in German. In: The proceedings of the $9^{\text {th }}$ International Conference on HSPG. Stanford University. p. 147-163, 2003.

LARSON, R. K. "Missing Prepositions" and the Analysis of English Free Relative Clauses. Linguistic Inquiry, 18 (2), 1987.

LASNIK, H.; SAITO, M. Move-a: conditions on its applications and output. MIT Press, Cambridge, Mass, 1992.

MEDEIROS JUNIOR, P. Uma análise de relativas livres no Português: considerações sobre Caso e concordância. Anais do IV CONGRESSO INTERNACIONAL DA ABRALIN, Brasília, p. 1397-1407, 2005a.

MEDEIROS JUNIOR, P. Sobre sintagmas-Qu e Relativas Livres no Português. Dissertação (Mestrado). UnB, Brasília - DF, 2005 b.

MEDEIROS JUNIOR, P. O caso das relativas e o caso nas relativas: uma análise minimalista de relativas livres e sintagmas-Qu no português brasileiro. In: TRAVAGLIA, L.C.; BERTOLDO, E.S.; MUSSALIM, F.; ALVES, M.; ARAÚJO, M. V. (Orgs.). Lingüística: caminhos e descaminhos em perspectiva. Uberlândia: EDUFU, 2006.

MIOTO, C. As interrogativas no português brasileiro e o critério WH. Letras de Hoje. Porto Alegre. v. 29, n. 2, p. 19-33, 1994.

MIYAGAWA, S. On the EPP. In: Perspectives on Phases. MIT Working Papers in Linguistics, 49. p. 201-235, 2005.

MÓIA, T. A sintaxe das orações relativas sem antecedente expresso no português. In: Quatro estudos em sintaxe do português. Lisboa: Edições Colibri, 1996.

OITICICA, J. Um ponto de análise: palavras sintéticas. In: NEY, J. L. (1956). Guia de análise sintática. Rio: Simões, 1947. p. 152-162.

RADFORD, A. Minimalist Syntax. Exploring the structure of English. Cambridge University Press, UK, 2004. 
RIEMSDIJK, H. V. Free Relatives. SynCom Case 44, 2000.

RIZZI, L. Residual verb second and the Wh criterion. Technical Reports in Formal and Computational Linguistics 2, University of Geneva, 1991.

RIZZI, L. The fine structure of the left periphery. MS, 1995.

ROCHA, Mari Lucia D. F. Sintagmas QU em interrogativas indiretas e relativas livres do português. 1990. Dissertação (Mestrado) - UnB, Brasília.

ROORYCK, J. Generalized transformations and the Wh-cycle: free relatives as bare wh-CPs, In: C. J.- ZWART (Ed.). Minimalism and Kayne's Asymmetry Hypothesis. GAGL 37 - p. 195-208, 1994.

SAUERLAND, U. The Matching Prefference. MIT, MS, 1996.

VERGNAUD, J. R. French Relative Clauses. Doctoral Dissertation, MIT, 1974.

VOGEL, R. Towards an Optimal Typology of the Free Relatives Construction. IATL 8. Papers from the Sixteenth Annual Conference and from The Research Workshop of the Israel Science Foundation 'The Syntax and Relative Clause Constructions'. Ed. Alexander Grosu. Tel Aviv University. p. 107-119, 2001.

VOGEL, R. Free Relative Constructions in OT Syntax. Resolving Conflicts in Grammars. In: FERRY, Caroline; FANSELOW, Gisbert (Eds.). Sonderheft Optimality Theory. Hamburg: Helmut Burske Verlag, 2002. p. 119-162.

VOGEL, R. 'Surface Matters. Case conflicts in Free Relative Constructions and Case Theory'. In: BRANDNER, Ellen; ZINSMEISTER, Heike (Eds.). New Perspectives on Case Theory, CSLI Publications. p. 269-299, 2003. 